\title{
Homocysteine-lowering vitamins do not lower plasma $S$-adenosylhomocysteine in older people with elevated homocysteine concentrations
}

\author{
Timothy J. Green ${ }^{1,2}$, C. Murray Skeaff ${ }^{2}$, Jennifer A. McMahon ${ }^{2}$, Bernard J. Venn ${ }^{2}$, Sheila M. Williams ${ }^{3}$, \\ Angela M. Devlin ${ }^{4}$ and Sheila M. Innis ${ }^{4}$ \\ ${ }^{1}$ Food, Nutrition, and Health, University of British Columbia, Vancouver, BC, Canada \\ ${ }^{2}$ Department of Human Nutrition, University of Otago, Dunedin, New Zealand \\ ${ }^{3}$ Department of Preventive and Social Medicine, University of Otago, Dunedin, New Zealand \\ ${ }^{4}$ Department of Paediatrics, University of British Columbia, Vancouver, BC, Canada
}

(Received 28 July 2009 - Revised 2 November 2009 - Accepted 20 November 2009 - First published online 21 January 2010)

\begin{abstract}
Elevated plasma total homocysteine (tHcy) is a risk factor for vascular disease but lowering tHcy with B-vitamins, including folate, has generally not reduced vascular events in secondary prevention trials. Elevated plasma $S$-adenosylhomocysteine (AdoHcy) concentration may be a more sensitive indicator of vascular disease than plasma tHcy. However, unlike tHcy, plasma AdoHcy did not correlate with folate concentration in one study indicating that folate supplementation may not lower AdoHcy. Our aim was to determine whether providing B-vitamin supplements to healthy older people with elevated tHcy $(>13 \mu \mathrm{mol} / \mathrm{l})$ affects plasma AdoHcy and $S$-adenosylmethionine (AdoMet) concentrations. Healthy older participants ( $n$ 276; $\geq 65$ years) were randomised to receive a daily supplement containing folate $(1 \mathrm{mg})$, vitamin $\mathrm{B}_{12}(500 \mu \mathrm{g})$ and vitamin $\mathrm{B}_{6}(10 \mathrm{mg})$, or placebo, for 2 years. Of these participants, we selected the first fifty participants in each treatment group and measured plasma AdoHcy and AdoMet. Plasma tHcy was $4.4(95 \%$ CI 3.2, 5.6; $P<0.001) \mu \mathrm{mol} / 1$ lower at 2 years in the vitamins group compared with the placebo group. At 2 years, there were no significant differences in plasma AdoMet $(+4 \%$ (95\% CI $-2,11) ; P=0 \cdot 19)$, AdoHcy $(-1 \%(95 \% \mathrm{CI}-10,8)$; $P=0.61)$ or the AdoMet:AdoHcy ratio $(0.22(95 \% \mathrm{CI}-0.04,0.49) ; P=0.10)$ between the two groups. In conclusion, B-vitamin supplementation of older people lowered plasma tHcy but had no effect on plasma AdoMet or AdoHcy concentration. If elevated plasma AdoHcy is detrimental, this may explain why B-vitamins have generally failed to reduce vascular events in clinical trials.
\end{abstract}

$S$-Adenosylhomocysteine: $S$-Adenosylmethionine: Homocysteine: B vitamins: Clinical trials: Older persons

Observational evidence indicates that an elevated circulating total homocysteine (tHcy) concentration is a risk factor for coronary, cerebral and peripheral vascular disease ${ }^{(1)}$. Homocysteine may be lowered by taking B-vitamin supplements containing folate with or without vitamins $B_{12}$ or $\mathrm{B}_{6}{ }^{(2)}$. However, taking homocysteine-lowering vitamins has generally not reduced vascular events in secondary prevention trials ${ }^{(3,4)}$. Recently, it has been proposed that plasma $S$-adenosylhomocysteine (AdoHcy) might be a more sensitive indicator of cardiovascular risk than plasma tHcy ${ }^{(5,6)}$. Kerins et al. ${ }^{(5)}$ reported that plasma AdoHcy, but not tHcy, was markedly higher among patients with vascular disease $(40.0 \mathrm{nmol} / \mathrm{l}$ and $12.8 \mu \mathrm{mol} / \mathrm{l}$, respectively, $n$ 30) than among healthy control subjects $(27.0 \mathrm{nmol} / \mathrm{l}$ and $11.0 \mu \mathrm{mol} / \mathrm{l}$, respectively, $n$ 29).

AdoHcy is the immediate precursor of homocysteine and is formed when $S$-adenosylmethionine (AdoMet) donates a methyl group to a variety of acceptors including DNA, a reaction catalysed by DNA methyltransferases. AdoHcy is an inhibitor of DNA methyltransferase ${ }^{(7)}$. Of importance, elevated concentrations of AdoHcy have been associated with global leucocyte DNA hypomethylation in male patients with atherosclerosis ${ }^{(8)}$, and AdoHcy is also more strongly associated with lymphocyte global DNA methylation levels than plasma $\mathrm{tHcy}^{(9)}$. DNA methylation influences gene expression and altered methylation has been implicated in the aetiology of several diseases including atherosclerosis. Whereas high plasma AdoHcy has been associated with unfavourable outcomes, plasma AdoMet has been positively associated with vascular function in elderly people with several CVD risk factors ${ }^{(10)}$. Using both metabolites, the ratio of plasma AdoMet:AdoHcy was found to be lower in patients with peripheral arterial occlusive disease compared with a control group ${ }^{(11)}$, which prompts the importance of studies to address whether altered AdoMet:AdoHcy ratio can be normalised in individuals at risk with B-vitamin supplementation.

Elevations in plasma tHcy are usually paralleled by an increase in plasma AdoHcy ${ }^{(8,9,12)}$. However, in one study, plasma folate was inversely correlated with tHcy, but not with AdoHcy ${ }^{(13)}$ suggesting that plasma AdoHcy may, at least in some conditions, be independent of folate status. 
If elevated AdoHcy is an important risk factor contributing to atherosclerosis, but is not influenced by supplementation with B-vitamins, then B-vitamin supplementation would not be expected to lower CVD risk ${ }^{(6,13)}$.

In the present study, our aim was to determine whether lowering tHcy with folate, vitamin $\mathrm{B}_{12}$ and $\mathrm{B}_{6}$ over 2 years in healthy older individuals known to have moderate hyperhomocysteinaemia alters not only plasma tHcy, but also plasma AdoHcy and AdoMet.

\section{Subjects and methods}

\section{Participants}

The present study was conducted according to the guidelines laid down in the Declaration of Helsinki, and all procedures involving human participants were approved by The University of Otago Human Ethics Committee. The work presented here is part of a larger study that was designed to examine the effects of B-vitamin supplementation on cognition in older people ${ }^{(14,15)}$. Briefly, men and women aged 65 years or older were recruited from Dunedin and surrounds. People were ineligible to participate if they had suspected dementia, were taking vitamin supplements containing folic acid, vitamin $\mathrm{B}_{12}$ or $\mathrm{B}_{6}$, were being treated for depression, had a history of stroke or transient ischaemic attacks or had diabetes. At screening, a blood sample was taken after an overnight fast and analysed for plasma tHcy and creatinine. Participation required a tHcy concentration greater than $13 \mu \mathrm{mol} / \mathrm{l}$. People with a plasma creatinine concentration exceeding $133 \mu \mathrm{mol} / \mathrm{l}$ (men) and $115 \mu \mathrm{mol} / \mathrm{l}$ (women) were excluded.

\section{Study design}

Participants meeting the inclusion criteria were stratified using the median values of age and tHcy concentration from the screening population and then randomised to treatment. The treatments were capsules containing either B-vitamins (1000 $\mu \mathrm{g}$ L-5-methyltetrahydrofolate, $500 \mu \mathrm{g}$ cyanocobalamin and $10 \mathrm{mg}$ pyridoxine) or a placebo. Capsules were supplied by Merck Eprova AG (Schaffhausen, Switzerland). Participants were instructed to take one capsule per day for 2 years. Compliance was assessed by counting returned capsules.

\section{Blood collection and laboratory methods}

A fasting blood sample was collected at screening, baseline and at 2 years. Blood was collected into evacuated tubes containing EDTA and kept on ice. Within $2 \mathrm{~h}$ of collection, plasma was separated from whole blood by centrifugation at $1650 \mathrm{~g}$, for $15 \mathrm{~min}$ at $4^{\circ} \mathrm{C}$. Plasma was aliquoted into cryovials and stored at $-80^{\circ} \mathrm{C}$ until analysed. Plasma samples were analysed for tHcy and creatinine at screening. Plasma samples were analysed for metabolites and vitamins at baseline and at 2 years. Plasma tHcy was measured using an IMx instrument and kits (Abbott Laboratories, Abbott Park, IL, USA). Folate was analysed using the microbiological method on 96-well microplates ${ }^{(16)}$. Vitamin $\mathrm{B}_{12}$ was measured using the ADVIA ${ }^{\circledR}$ Centaur ${ }^{\mathrm{TM}}$ vitamin $\mathrm{B}_{12}$ assay (Siemens Healthcare Diagnostics Deerfield, IL, USA), and creatinine was analysed colorimetrically using Roche diagnostic kits
(Roche Diagnostics, Basel, Switzerland). Genotyping for the methylenetetrahydrofolate reductase $677 \mathrm{C} \rightarrow \mathrm{T}$ polymorphism was performed using methods described previously ${ }^{(17)}$.

Plasma samples for AdoHcy and AdoMet were analysed in a subset of the 276 participants who had taken part in the cognition study. One hundred samples were analysed, which consisted of plasma from the first fifty participants randomised to each treatment group who had completed the study and for whom there was an aliquot of plasma which had undergone no freeze-thaw cycles. Samples for AdoHcy and AdoMet were shipped frozen on dry ice from New Zealand to the Metabolomics Laboratories of the Child and Family Research Institute of the University of British Columbia. Samples were analysed for AdoHcy and AdoMet using isotope dilution high-performance liquid chromatographtandem MS using a Quattro Micro tandem mass spectrometer configured with an electrospray source coupled to an Aquity high-performance liquid chromatography equipped with a thermostated autosampler. Internal standards were AdoHcy ${ }^{13} \mathrm{C}_{5}$ prepared as described ${ }^{(18,19)}$ and AdoMet ${ }^{2} \mathrm{H}_{3}$ (CDN Isotopes, Inc., Pointe Claire, QC, Canada). The mass spectrometer was operated in positive electrospray in selected reaction mode using the transitions of $\mathrm{m} / \mathrm{z}, 390-250$ for AdoMet and $m / z, 390-250,402-250$ for AdoMet ${ }^{2} \mathrm{H}_{3}$, and 385-136 m/z for AdoHcy and $\mathrm{m} / \mathrm{z}, 390-136$ for AdoHcy ${ }^{13} \mathrm{C}_{5}$. The inter- and intra-assay variations for AdoHcy were 5.0 and $4.2 \%$, respectively, and for AdoMet were 3.0 and $3 \cdot 1 \%$, respectively.

In the present study, care was taken to ensure that sample aliquots for analysis of AdoMet and AdoHcy had never undergone any freeze-thaw cycle since this can lead to loss of AdoMet and an increase in AdoHcy; the error introduced is much greater for AdoHcy because of its lower concentration in plasma. Stability studies using the same plasma samples in repeat freeze-thaw cycles, keeping the thaw cycle to a minimum to enable sample aliquoting, showed that under our conditions the loss of AdoMet was 3.5, 9.8 and $18.8 \%$ and gain in AdoHcy in the same samples was 16.6, 31.8 and $39.4 \%$ over 1,2 and 3 freeze-thaw cycles, respectively. While the loss in nmol/l AdoMet was similar to the nmol/l increase in AdoHcy, the fivefold lower concentration of AdoHcy introduces much greater error to AdoHcy than for AdoMet.

\section{Statistical analysis}

Plasma AdoHcy and AdoMet were not normally distributed and were transformed using the natural logarithm. Pearson correlation coefficients were used to determine associations between biochemical measures at baseline. Multiple regression analysis, adjusting for the baseline values age, sex and TT genotype for the methylenetetrahydrofolate reductase $677 \mathrm{C} \rightarrow \mathrm{T}$ polymorphism, was used to estimate the differences at 2 years between the placebo and treated groups. To determine whether renal function influenced response to treatment, we divided baseline plasma creatinine concentration into quartiles. We then ran regression models for each of AdoHcy and AdoMet, which included an interaction term for quartile of plasma creatinine and treatment. Results were considered significant at $P<0 \cdot 05$. All analyses were undertaken using STATA 9.0 software for Macintosh (Stata Corp., College Station, TX, USA) ${ }^{(20)}$. 


\section{Results}

Baseline characteristics of the study participants are presented in Table 1. Overall, $85 \%$ of participants took at least $95 \%$ of their study capsules. Associations between plasma AdoHcy and metabolite and vitamin concentrations at baseline are shown in Fig. 1. One participant with a very high AdoMet $(380 \mathrm{nmol} / \mathrm{l}$; $>3 \mathrm{SD}$ from the mean) was excluded from the correlation analysis. There were significant positive correlations at baseline between plasma creatinine and each of tHcy ( $r$ 0.34; $P<0.001)$, AdoMet $(r 0.48 ; P<0.001)$ and AdoHcy ( $r$ 0.65; $P<0.001$ ). Plasma AdoHcy was associated with AdoMet $(r 0.61 ; P<0.001)$ and tHcy $(r 0.42 ; P<0.001)$. Neither plasma folate $(r-0 \cdot 10 ; P=0 \cdot 34)$ nor plasma vitamin $\mathrm{B}_{12}(r 0.02 ; P=0.80)$ was associated with AdoHcy. Plasma tHcy was not correlated with plasma folate $(r-0 \cdot 19$; $P=0 \cdot 10)$ or vitamin $\mathrm{B}_{12}(r-0 \cdot 20 ; P=0 \cdot 10)$.

The main biochemical results of the intervention are presented in Table 2. Plasma tHcy concentration at 2 years, after adjustment for baseline values, age, sex and MTHFR C677T genotype, was $4.4 \mu \mathrm{mol} / 1$ (95\% CI 3.2, 5.6) lower in the vitamins group compared with the placebo group $(P<0.001)$. Plasma folate and vitamin $\mathrm{B}_{12}$ concentrations were $54.6 \mathrm{nmol} / 1 \quad(95 \%$ CI $47.7,61.4 ; P<0.001)$ and $346 \mathrm{pmol} / 1$ (95\% CI 280, 413; $P<0.001$ ) higher, respectively, in the vitamins group compared with the placebo group. At 2 years, there was no difference in plasma AdoHcy $(-1 \%$ (95\% CI $-10,8 \%) ; P=0.82)$, AdoMet (4\% (95\% CI -2 , $11 \%) ; P=0.19)$ or the AdoMet:AdoHcy ratio between the groups $(0.22$ (95\% CI $-0.04,0.49) ; P=0 \cdot 10)$. There was no significant interaction $(P>0.05)$ between quartile of baseline plasma creatinine and treatment for either AdoMet or AdoHcy indicating that baseline plasma creatinine did not influence treatment response.

\section{Discussion}

Although many investigators have shown that B-vitamins, particularly folic acid, lower plasma tHcy, this is the first study to examine the effects of supplements containing folate, and vitamins $\mathrm{B}_{12}$ and $\mathrm{B}_{6}$ on AdoHcy concentrations in people with moderately elevated hyperhomocysteine concentrations $^{(2)}$. The present study clearly demonstrates that despite a nearly $4.4 \mu \mathrm{mol} / \mathrm{l}$ drop in plasma tHcy in the treated group relative to placebo group, there was no effect of B-vitamin supplementation on plasma concentrations of AdoHcy or AdoMet. Altered DNA methylation has been implicated in the aetiology of atherosclerosis, and a decreased AdoMet:AdoHcy ratio has also been suggested as an indicator of diminished cellular methylating capacity ${ }^{(21)}$. B-vitamins did not significantly alter the plasma AdoMet: AdoHcy ratio in the present study, although it approached significance $(+0 \cdot 22$; $P=0 \cdot 10$ ). However, AdoHcy may be a more relevant indicator of cellular methylation capacity than the AdoMet:AdoHcy ratio, as plasma AdoHcy levels have been shown to correlate with lymphocyte global DNA methylation levels ${ }^{(9)}$ and AdoHcy is an inhibitor of methyltransferases.

In apparent contrast to the present findings, Stabler et al. ${ }^{\text {(22) }}$ reported that high-dose oral vitamin $B_{12}(1000 \mu \mathrm{g} / \mathrm{d})$ over 3 months lowered plasma AdoHcy by about $10 \%$ relative to baseline in older people ( $n$ 27). The effect appeared to be confined to people ( $n$ 27) with suboptimal vitamin $B_{12}$ status as indicated by high-serum methylmalonic acid concentrations $(>271 \mathrm{nmol} / \mathrm{l})$. Different $\mathrm{B}_{12}$ status of participants in the two studies seems unlikely to account for the contrasting findings of $\mathrm{B}_{12}$ supplementation on AdoHcy, because mean plasma $\mathrm{B}_{12}$ concentrations in the high methylmalonic acid group in the study by Stabler et al. were similar to the mean concentration at baseline in the present study participants $(312 \mathrm{pmol} / \mathrm{l} c f$ $295 \mathrm{pmol} / \mathrm{l}$, respectively). However, the present findings are in agreement with those of Stabler et al. ${ }^{(22)}$ who found that vitamin $B_{12}$ supplementation, irrespective of $B_{12}$ status, lowered plasma tHcy but had no effect on plasma AdoMet or on the ratio of AdoMet:AdoHcy in people without elevated methylmalonic acid.

Although B-vitamin supplementation did not alter plasma AdoHcy concentrations, plasma tHcy and plasma AdoHcy were moderately correlated in the present study ( $r 0.4)$. Correlations between plasma tHcy and plasma AdoHcy in other studies have ranged from $r 0 \cdot 37-0 \cdot 81^{(5,13,22,23)}$. The inability of B-vitamins to lower plasma AdoHcy despite large decreases in plasma tHcy suggests that high-dose B-vitamin supplementation does not override the factors that determine plasma AdoHcy across the usual range of plasma tHcy

Table 1. Baseline characteristics of the participants

(Mean values and standard deviations)

\begin{tabular}{|c|c|c|c|c|c|c|c|c|}
\hline \multirow[b]{2}{*}{ Variable } & \multicolumn{4}{|c|}{ Placebo ( $n 50)$} & \multicolumn{4}{|c|}{ Vitamins ( $n 50)$} \\
\hline & Mean & SD & $n$ & $\%$ & Mean & SD & $n$ & $\%$ \\
\hline Age (years) & $74 \cdot 4$ & $5 \cdot 7$ & & & $73 \cdot 4$ & $5 \cdot 3$ & & \\
\hline Female sex & & & 23 & 46 & & & 27 & 54 \\
\hline BMI $\left(\mathrm{kg} / \mathrm{m}^{2}\right)$ & $27 \cdot 1$ & $4 \cdot 0$ & & & $26 \cdot 8$ & 4.7 & & \\
\hline Current smoker & & & 0 & 0 & & & 0 & 0 \\
\hline Alcohol (drinks per week)* & $5 \cdot 6$ & $8 \cdot 6$ & & & $5 \cdot 0$ & 6.7 & & \\
\hline \multicolumn{9}{|l|}{ Education attained } \\
\hline$<3$ years secondary & & & 16 & 32 & & & 17 & 34 \\
\hline$\geq 3$ years secondary & & & 5 & 10 & & & 5 & 10 \\
\hline Tertiary & & & 29 & 58 & & & 63 & 56 \\
\hline Plasma creatinine $(\mu \mathrm{mol} / \mathrm{l})$ & 61 & 17 & & & 68 & 22 & & \\
\hline MTHFR C677T TT & 1 & 2 & & & & & 9 & 18 \\
\hline
\end{tabular}

MTHFR C677T TT, methylenetetrahydrofolate reductase C677T, homozygous TT genotype.

* One drink defined as $15 \mathrm{ml}$ of pure alcohol; $360 \mathrm{ml}$ beer, $150 \mathrm{ml}$ wine or $45 \mathrm{ml}$ distilled spirits. 
(a)

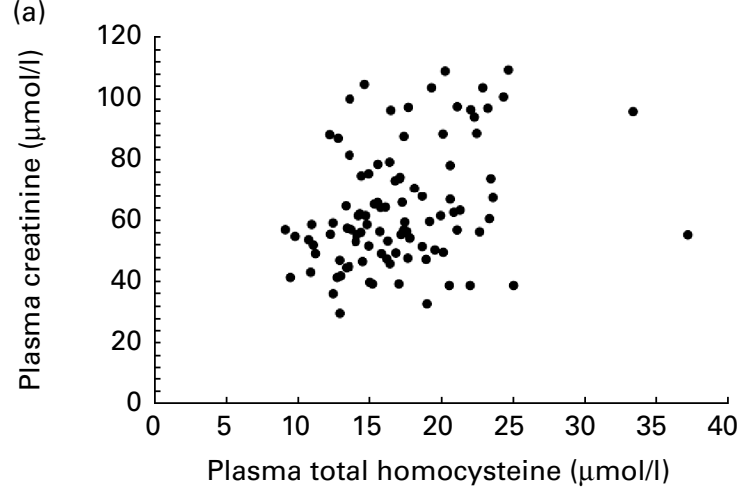

(c)

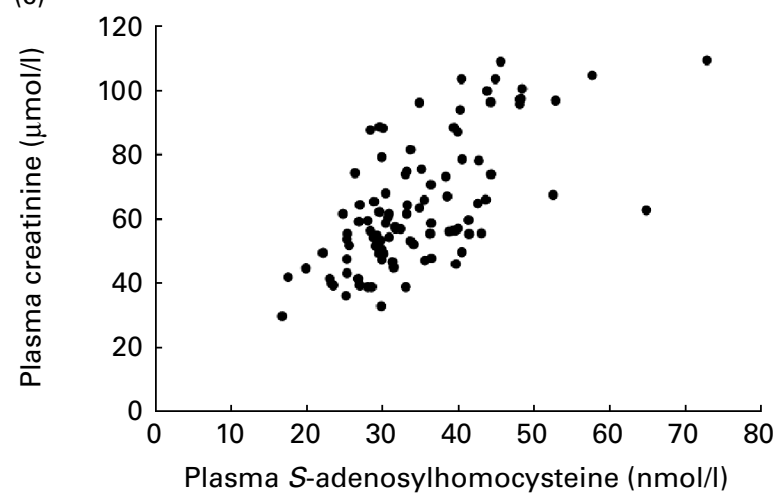

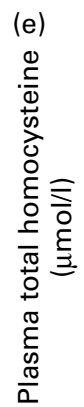

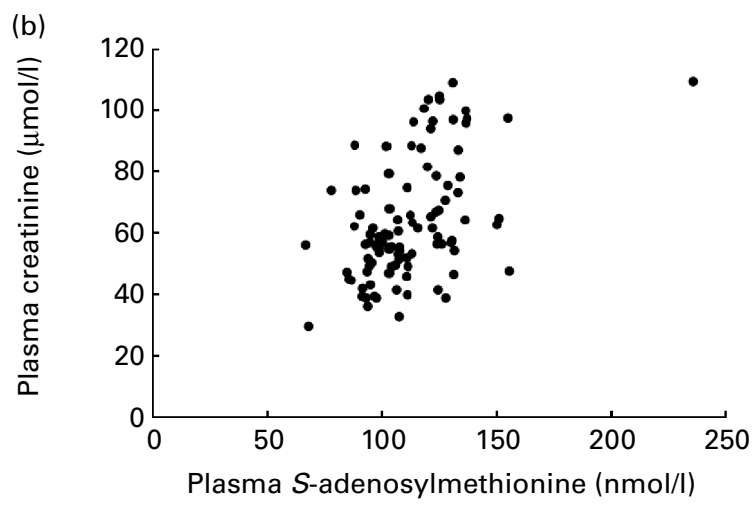

(d)

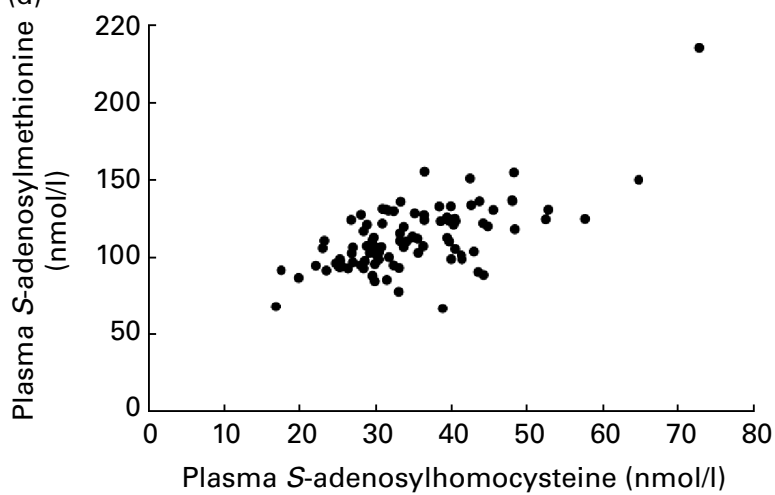

(f)

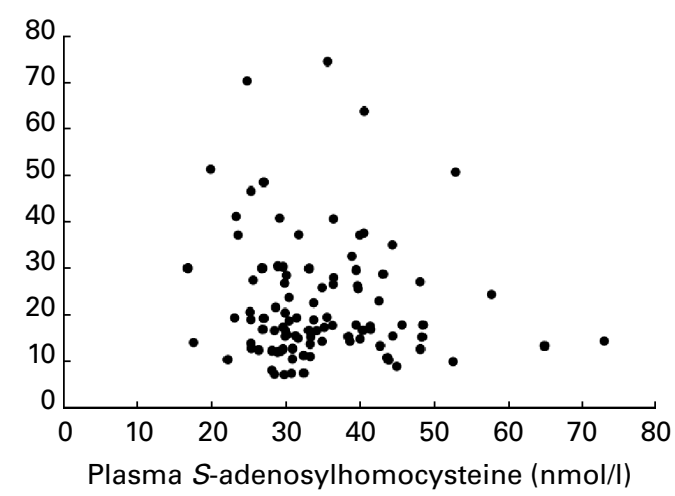

Fig. 1. Correlation between plasma metabolites, creatinine and folate at baseline ( $n$ 99). (a) $r 0.34 ; P<0.001$. (b) $r 0.48 ; P<0.001$. (c) $r 0.65$; $P<0.001$. (d) $r 0.61$; $P<0.001$. (e) $r 0.42 ; P<0.001$. (f) $r-0.10 ; P=0.34$.

concentrations. Consistent with the findings of Becker et al. ${ }^{(13)}$, plasma AdoHcy was not associated with plasma folate or vitamin $B_{12}$. The lack of an association in the present study between plasma tHcy and plasma folate or $\mathrm{B}_{12}$ differs from other study results ${ }^{(13,22,24)}$ and probably reflects the fact that participants in the present study did not cover the full range of plasma tHcy concentrations, rather only the upper range ( $\geq 13 \mu \mathrm{mol} / \mathrm{l})$. It is possible that this also explains the lack of cross-sectional association at baseline between plasma AdoHcy and plasma folate and plasma vitamin $\mathrm{B}_{12}$.

Despite excluding individuals with high creatinine concentrations from participating in the present study, plasma tHcy and plasma AdoHcy were strongly correlated with plasma creatinine, an indicator of renal function. This relationship is well described $^{(25)}$. However, it is interesting to note that in the present study and in those by others, plasma creatinine is more strongly associated with plasma AdoHcy than with plasma tHcy ${ }^{(22,25)}$. If renal function is the primary determinant of plasma AdoHcy, this may explain why B-vitamins failed to lower plasma AdoHcy concentrations in the present study group. Plasma tHcy and plasma AdoHcy are markedly elevated in renal disease. Folic acid will lower plasma tHcy in renal patients but not to normal levels ${ }^{(26)}$. The effect of folic acid on plasma AdoHcy in renal patients is unknown.

Strengths of the present study include the long duration (2 years), high compliance and high baseline plasma tHcy concentrations that dropped substantially with B-vitamin supplementation. New Zealand does not have mandatory folic acid fortification so that any effect of folate supplementation on plasma AdoHcy should be more apparent than in a country with mandatory fortification such as the US, where blood folate concentrations are higher and plasma 
Table 2. Plasma metabolites and vitamins in older adults administered B-vitamins or placebo for 2 years

\begin{tabular}{|c|c|c|c|c|c|c|c|}
\hline & \multirow[b]{2}{*}{ Treatment } & \multicolumn{2}{|c|}{ Baseline $(n 50)^{*}$} & \multicolumn{2}{|c|}{2 years $(n 50)$} & \multirow[b]{2}{*}{ Adjusted difference vitamin cf placebo } & \multirow[b]{2}{*}{$P$} \\
\hline & & Mean & SD & Mean & SD & & \\
\hline \multirow[t]{2}{*}{ Plasma tHcy $(\mu \mathrm{mol} / \mathrm{l})$} & Placebo & $17 \cdot 0$ & 4.4 & $15 \cdot 5$ & $3 \cdot 8$ & & \\
\hline & Vitamins & $17 \cdot 3$ & 4.9 & $11 \cdot 1$ & $2 \cdot 8$ & $-4.4(-5.6,-3.2) \dagger$ & $<0.001$ \\
\hline \multirow[t]{2}{*}{ Plasma folate $(\mathrm{nmol} / \mathrm{l})$} & Placebo & $23 \cdot 3$ & $14 \cdot 0$ & $20 \cdot 4$ & $10 \cdot 5$ & & \\
\hline & Vitamins & $22 \cdot 0$ & $12 \cdot 9$ & 74.8 & $21 \cdot 8$ & $54.6(47 \cdot 7,61.4) \dagger$ & $<0.001$ \\
\hline \multirow[t]{2}{*}{ Plasma $B_{12}(p m o l / l)$} & Placebo & 302 & 125 & 267 & 180 & & \\
\hline & Vitamins & 291 & 81 & 594 & 249 & $346(280,413) \dagger$ & $<0.001$ \\
\hline \multirow[t]{2}{*}{ Plasma AdoMet (nmol/l) } & Placebo & $114 \ddagger$ & 36 & $122 \ddagger$ & 36 & & \\
\hline & Vitamins & $108 \ddagger$ & 16 & $121 \ddagger$ & 26 & $1.04(0.98,1.11) \S$ & 0.194 \\
\hline \multirow[t]{2}{*}{ Plasma AdoHcy (nmol/l) } & Placebo & $34.9 \ddagger$ & $13 \cdot 2$ & $39 \cdot 0 \neq$ & $16 \cdot 7$ & & \\
\hline & Vitamins & $32.9 \ddagger$ & 7.5 & $35.9 \ddagger$ & $12 \cdot 0$ & $0.99(0.90,1.08) \S$ & 0.817 \\
\hline \multirow[t]{2}{*}{ Plasma AdoMet:AdoHcy } & Placebo & $3 \cdot 28$ & 0.81 & $3.95 \ddagger$ & 0.82 & & \\
\hline & Vitamins & 3.30 & 0.69 & $4 \cdot 37 \ddagger$ & 1.00 & $0.22(-0.04,0.49) \dagger$ & 0.094 \\
\hline
\end{tabular}

tHCY, total homocysteine; AdoMet, S-adenosylmethionine;Adohcy, S-adenosylhomocysteine.

* There were no significant differences between the placebo and vitamins groups at baseline (Student's $t$ test)

†Difference between intervention and control groups at 2 years (multiple regression analysis with adjustment for baseline values, age, sex and MTHFR genotype)

$\ddagger$ Geometric mean.

$\S$ Ratio of geometric means of the intervention groups relative to the control groups at 2 years (multiple regression analysis with adjustment for baseline values, age, sex and MTHFR genotype).

tHcy is lower ${ }^{(27)}$. For example, in the study by Stabler et al. ${ }^{(22)}$, baseline plasma tHcy was $10.7 \mu \mathrm{mol} / \mathrm{l}$ and serum folate was $46 \mathrm{nmol} / \mathrm{l}$. In comparison with that study, our participants had higher tHcy $(17 \cdot 1 \mu \mathrm{mol} / \mathrm{l})$ and lower serum folate $(22 \mathrm{nmol} / \mathrm{l})$. We acknowledge that the present study has a number of limitations, the first being that plasma AdoHcy may not reflect tissue intracellular AdoHcy concentrations. Mouse models of hyperhomocysteinaemia have increased AdoHcy and reduced AdoMet:AdoHcy ratios in liver ${ }^{(28,29)}$; however, it is not known whether this is also accompanied by changes in plasma AdoMet/AdoHcy and AdoHcy. Furthermore, the tissue source of plasma AdoHcy is not known. Second, we screened at baseline for plasma tHcy and not for plasma AdoHcy. It is possible that individuals with higher baseline plasma AdoHcy may respond to B-vitamin supplementation. However, plasma AdoHcy is correlated with plasma tHcy and although not directly comparable because of methodological differences, it would appear that plasma AdoHcy concentrations in the present study were higher or similar to those reported in other studies of older adults ${ }^{(5,13,22)}$. Third, based on plasma folate and vitamin $\mathrm{B}_{12}$ concentrations, there was no evidence of frank folate or vitamin $B_{12}$ deficiency in our participants. It is possible that an effect of B-vitamin supplementation on plasma AdoHcy might occur in people with poorer B-vitamin status, as suggested by the study by Stabler et al. ${ }^{(22)}$. Finally, we did not assess the effect of B-vitamin supplementation on either global DNA methylation or gene-specific changes in DNA methylation. Hyperhomocysteinaemia and reduced AdoMet:AdoHcy ratio and increased AdoHcy are associated with gene-specific changes in DNA methylation in the liver of mice ${ }^{(29)}$. Studies in human subjects have been equivocal. Although low folate status or elevated plasma tHcy has been associated with lymphocyte DNA global hypomethylation ${ }^{(30)}$ especially in those TT for the common C677T MTHFR polymorphism ${ }^{(31)}$, giving folic acid has not consistently altered global DNA methylation in blood cells ${ }^{(30,32-35)}$.

In conclusion, although plasma AdoHcy was correlated with plasma tHcy, B-vitamin supplementation taken over a 2-year period did not lower plasma AdoHcy concentrations in older people despite a substantial drop in plasma tHcy concentrations. If elevated plasma AdoHcy is detrimental, either through a direct effect or through disturbances in cellular methylation capacity, this may explain why B-vitamins have generally failed to reduce vascular events in secondary prevention clinical trials. Another possibility is that AdoHcy is a sensitive indicator of renal insufficiency, which itself may be a much more important determinant of vascular disease than increased tHcy concentrations due to vitamin inadequacy.

\section{Acknowledgements}

An Otago Research Grant and a Child and Family Research Institute Nutrition Research Unit Award from Michael Smith Foundation for Health Research and Bristol-Myers Squibb Foundation Unrestricted Discovery Grant funded the present project. Eprova AG (Switzerland) provided the supplements. T. J. G., S. M. I. and C. M. S. conceived of the idea of the metabolite study; T. J. G., C. M. S. and J. A. M. conceived of the design of the larger randomised controlled trial; J. A. M. recruited the participants and carried out the intervention study; S. M. I. developed the assays for AdoMet and AdoHcy and supervised their analysis for the present study; S. M. W. performed the statistical analyses; B. J. V. and A. M. D. helped to interpret the data. T. J. G. wrote the first draft of the manuscript and all authors contributed to writing the final manuscript. None of the authors had a personal or financial conflict of interest.

\section{References}

1. McNulty H, Pentieva K, Hoey L, et al. (2008) Homocysteine, B-vitamins and CVD. Proc Nutr Soc 67, 232-237.

2. Homocysteine Lowering Trialists' Collaboration (2005) Dose-dependent effects of folic acid on blood concentrations of homocysteine: a meta-analysis of the randomized trials. Am J Clin Nutr 82, 806-812. 
3. Bonaa KH, Njolstad I, Ueland PM, et al. (2006) Homocysteine lowering and cardiovascular events after acute myocardial infarction. $N$ Engl J Med 354, 1578-1588.

4. Toole JF, Malinow MR, Chambless LE, et al. (2004) Lowering homocysteine in patients with ischemic stroke to prevent recurrent stroke, myocardial infarction, and death: the Vitamin Intervention for Stroke Prevention (VISP) randomized controlled trial. JAMA 291, 565-575.

5. Kerins DM, Koury MJ, Capdevila A, et al. (2001) Plasma $S$-adenosylhomocysteine is a more sensitive indicator of cardiovascular disease than plasma homocysteine. Am J Clin Nutr 74, 723-729.

6. Wagner C \& Koury MJ (2007) S-Adenosylhomocysteine: a better indicator of vascular disease than homocysteine? Am J Clin Nutr 86, 1581-1585.

7. De Cabo SF, Santos J \& Fernandez-Piqueras J (1995) Molecular and cytological evidence of $S$-adenosyl- $L$-homocysteine as an innocuous undermethylating agent in vivo. Cytogenet Cell Genet 71, 187-192.

8. Castro R, Rivera I, Struys EA, et al. (2003) Increased homocysteine and $S$-adenosylhomocysteine concentrations and DNA hypomethylation in vascular disease. Clin Chem 49, 1292-1296.

9. Yi P, Melnyk S, Pogribna M, et al. (2000) Increase in plasma homocysteine associated with parallel increases in plasma $S$-adenosylhomocysteine and lymphocyte DNA hypomethylation. J Biol Chem 275, 29318-29323.

10. Spijkerman AM, Smulders YM, Kostense PJ, et al. (2005) $S$-adenosylmethionine and 5-methyltetrahydrofolate are associated with endothelial function after controlling for confounding by homocysteine: the Hoorn Study. Arterioscler Thromb Vasc Biol 25, 778-784.

11. Loehrer FM, Tschopl M, Angst CP, et al. (2001) Disturbed ratio of erythrocyte and plasma $S$-adenosylmethionine/ $S$-adenosylhomocysteine in peripheral arterial occlusive disease. Atherosclerosis 154, 147-154.

12. Finkelstein JD, Kyle WE \& Harris BJ (1974) Methionine metabolism in mammals: regulatory effects of $S$-adenosylhomocysteine. Arch Biochem Biophys 165, 774-779.

13. Becker A, Smulders YM, Teerlink T, et al. (2003) $S$-adenosylhomocysteine and the ratio of $S$-adenosylmethionine to $S$-adenosylhomocysteine are not related to folate, cobalamin and vitamin $\mathrm{B}_{6}$ concentrations. Eur J Clin Invest 33, 17-25.

14. McMahon JA, Green TJ, Skeaff CM, et al. (2006) A controlled trial of homocysteine lowering and cognitive performance. $N$ Engl J Med 354, 2764-2772.

15. Green TJ, McMahon JA, Skeaff CM, et al. (2007) Lowering homocysteine with B vitamins has no effect on biomarkers of bone turnover in older persons: a 2-y randomized controlled trial. Am J Clin Nutr 85, 460-464.

16. O’Broin S \& Kelleher B (1992) Microbiological assay on microtitre plates of folate in serum and red cells. $J$ Clin Pathol 45, 344-347.

17. Venn BJ, Mann JI, Williams SM, et al. (2002) Assessment of three levels of folic acid on serum folate and plasma homocysteine: a randomised placebo-controlled double-blind dietary intervention trial. Eur J Clin Nutr 56, 748-754.

18. Jiang Z, Liang Q, Luo G, et al. (2009) HPLC-electrospray tandem mass spectrometry for simultaneous quantitation of eight plasma aminothiols: application to studies of diabetic nephropathy. Talanta 77, 1279-1284.
19. Struys EA, Jansen EE, de Meer K, et al. (2000) Determination of $S$-adenosylmethionine and $S$-adenosylhomocysteine in plasma and cerebrospinal fluid by stable-isotope dilution tandem mass spectrometry. Clin Chem 46, 1650-1656.

20. Vickers AJ \& Altman DG (2001) Statistics notes: analysing controlled trials with baseline and follow up measurements. BMJ 323, 1123-1124.

21. Hershfield MS, Kredich NM, Koller CA, et al. (1983) $S$-Adenosylhomocysteine catabolism and basis for acquired resistance during treatment of T-cell acute lymphoblastic leukemia with $2^{\prime}$-deoxycoformycin alone and in combination with 9-beta-D-arabinofuranosyladenine. Cancer Res 43, 3451-3458.

22. Stabler SP, Allen RH, Dolce ET, et al. (2006) Elevated serum $S$-adenosylhomocysteine in cobalamin-deficient elderly and response to treatment. Am J Clin Nutr 84, 1422-1429.

23. Jabs K, Koury MJ, Dupont WD, et al. (2006) Relationship between plasma $S$-adenosylhomocysteine concentration and glomerular filtration rate in children. Metabolism 55, 252-257.

24. Selhub J, Jacques PF, Wilson PW, et al. (1993) Vitamin status and intake as primary determinants of homocysteinemia in an elderly population. JAMA 270, 2693-2698.

25. Stabler SP \& Allen RH (2004) Quantification of serum and urinary $S$-adenosylmethionine and $S$-adenosylhomocysteine by stable-isotope-dilution liquid chromatography-mass spectrometry. Clin Chem 50, 365-372.

26. van Guldener C \& Robinson K (2000) Homocysteine and renal disease. Semin Thromb Hemost 26, 313-324.

27. Ganji V \& Kafai MR (2009) Demographic, lifestyle, and health characteristics and serum B vitamin status are determinants of plasma total homocysteine concentration in the post-folic acid fortification period, 1999-2004. J Nutr 139, 345-352.

28. Dayal S, Bottiglieri T, Arning E, et al. (2001) Endothelial dysfunction and elevation of $S$-adenosylhomocysteine in cystathionine beta-synthase-deficient mice. Circ Res 88, 1203-1209.

29. Devlin AM, Bottiglieri T, Domann FE, et al. (2005) Tissuespecific changes in $\mathrm{H} 19$ methylation and expression in mice with hyperhomocysteinemia. J Biol Chem 280, 25506-25511.

30. Jacob RA, Gretz DM, Taylor PC, et al. (1998) Moderate folate depletion increases plasma homocysteine and decreases lymphocyte DNA methylation in postmenopausal women. J Nutr 128, 1204-1212.

31. Friso S, Choi SW, Girelli D, et al. (2002) A common mutation in the 5,10-methylenetetrahydrofolate reductase gene affects genomic DNA methylation through an interaction with folate status. Proc Natl Acad Sci USA 99, 5606-5611.

32. Auxume J, Smith SS, Poribgny IP, et al. (2007) Methylene tetrahydrofolate reductase 677TT genotype and folate interact to lower global DNA methylation in you Mexican American women. Nutr Res 27, 13-17.

33. Rampersaud GC, Kauwell GP, Hutson AD, et al. (2000) Genomic DNA methylation decreases in response to moderate folate depletion in elderly women. Am J Clin Nutr 72, 998-1003.

34. Shelnutt KP, Kauwell GP, Gregory JF 3rd, et al. (2004) Methylenetetrahydrofolate reductase $677 \mathrm{C} \rightarrow \mathrm{T}$ polymorphism affects DNA methylation in response to controlled folate intake in young women. $J$ Nutr Biochem 15, 554-560.

35. Fenech M, Aitken C \& Rinaldi J (1998) Folate, vitamin $B_{12}$, homocysteine status and DNA damage in young Australian adults. Carcinogenesis 19, 1163-1171. 